\title{
Factors Affecting Time Spent on Discussing Patients at a Tumor Board: The Ugandan Head and Neck Cancer Experience
}

\author{
Adriane Kamulegeya ${ }^{1 *}$, Solomon Kibudde ${ }^{2}$, Victoria Walusansa ${ }^{2}$ and Jeff Otiti $^{2}$ \\ ${ }^{1}$ Oral Maxillofacial Surgery Unit, Akerere University College Health Sciences, Africa \\ ${ }^{2}$ Department of Medical Oncology, Uganda Cancer Institute, Uganda
}

Submission: May 11, 2017; Published: July 24, 2017

*Corresponding author: Adriane Kamulegeya, Oral Maxillofacial Surgery Unit, Makerere University College of Health Sciences, Kampala, Uganda, Tel: +256712 072432; Email: adrianek55@gmail.com

\begin{abstract}
Background: Multi disciplinary tumor boards (MDTBs) are becoming a standard in decision making on how the head and neck cancer patients ought to be managed. However, in developing countries this means a call on the few clinicians available to create time and attend these meetings. Therefore the time spent at these boards should be as brief, effective and beneficial as possible.

Objective: We decided to find out how we are doing at our tumor board and also establish the factors that affect time spent on discussing and concluding on treatment course of patients we see.

Design of the study: This was a cross-sectional study in which the time of discussion in minutes was captured by a single observer using a stop watch. The observer also captured the number of discussants.

Setting of the study: The study was conducted at the weekly head and neck tumor board at the Uganda Cancer Institute. Uganda Cancer Institute is a referral and biggest cancer management center that houses both medical and radiotherapy oncology services. It is located on the Mulago hill next to Mulago National referral hospital that does most of surgical oncology work in the country.

Subjects/participants: At the weekly head and neck tumor board, we have ear nose and throat surgeons, head and neck surgeons, oral and maxillofacial surgeons, medical oncologists, radiotherapy oncologists, senior house officers in these disciplines, nurses and at times
\end{abstract} ophthalmologists and pathologists. These constituted our study participants.

\section{Introduction}

Head and neck cancers are a varied group depending on the histopathological and/or anatomical definition one chooses to adopt. The oral cavity, oropharynx, nasopharynx, larynx and hypopharynx are most affected and often the histology is squamous cell carcinoma. Looking at them as a group their incidence worldwide varies dependent on gender, prevalence of smoking anatomic site and geographical region [1]. For instance oral cavity cancer age standardized rate (ASR) incidence is estimated at 6.9 in developed countries among men while it's at 4.6 in developing countries. Laryngeal cancer ASR is at 5.5 and 3.5 in developed and developing countries respectively. In Uganda Nasopharygeal carcinoma ASR is estimated at 2.4 and 1.3 for male and female respectively with an annual increase of about $12.4 \%$ yet the data only covers a small county [2]. Thus showing the growing importance of head and neck cancers.
Although the incidence ASR is lower in developing countries than developed, the ASR mortality is nearly equal showing the terrible prognosis these cancers portend in developing countries [3]. The reasons for this high mortality are multi-factorial ranging from late presentation, cultural beliefs, delayed referrals to appropriate health facilities and lack or frequent breakdown of facilities required in treatment of these cancers [4,5]. In addition to the few centers where such cases can be handled, most Sub Saharan African do not have concerted effort to have multi specialty teams and comprehensive pre treatment planning for both cancers and complex benign neoplasms. Multi disciplinary teams in cancer management have the advantages of offering the patients higher quality care in a more coordinated and timely manner [6]. Therefore they are being adopted as a standard of care in cancer management centers the world over. 
As the world becomes one global village the trend of multi disciplinary teams managing cancer patients has caught on even in the low income developing countries in which most Sub Saharan African countries fall [7]. This is against the back drop of poor staffing and remuneration levels in this region thus making extra demands on the time of the clinicians less palatable. It's against this back ground that we carried out this research to establish factors that affect the time of spent on discussing patient at our head and neck tumor board.

\section{Methods}

The head and neck tumor board meeting at the Uganda Cancer Institute (UCI) was founded in 2012 under the leadership of a senior head and neck surgeon. The meeting attracts different specialists including two oral maxillofacial surgeons, four medical oncologists, two radiation oncologists, a palliative care specialist and three head and neck surgeons. However, there is no regular pathologist committed to head and neck pathology to support discussions in this forum. The meeting is regularly attended by residents from the masters program at Makerere University in the Ear, Nose and Throat and maxillofacial surgery programs. The meeting is held once every week and lasts approximately two hours and typically the resident or specialist will give a brief clinical summary of a case (usually $3-5 \mathrm{~min}$ ) including relevant radiographic and pathologic findings, with subsequent discussion centered on therapeutic management. The patient is called in before the discussion so that a brief examination is done except for cases that are bed ridden. Remarkably, all patients referred with head and neck cancers to the UCI are reviewed at the head and neck tumor board meeting for purposes of streamlining care and coordinating the different modalities particularly surgery, chemotherapy and radiotherapy for head and neck cancers.

Data was collected prospectively during 30 consecutive multi-disciplinary head and neck tumor board meetings held at the UCI, accumulating a sample size of 144 patients. Between January and December 2014.

A single observer captured information on the time of discussion in minutes. The counting was started after presentation and physical examination of the patient. The duration of any discussion not considered relevant to the case was deducted. This included instances of questioning senior house officers to see their grasp of knowledge, teaching and sometimes jokes. If a case was discussed more than once in a meeting or subsequent meetings either due to new investigation results, need for input from another specialist who was away at the time of the initial discussion or review of histopathological specimen, the total sum of the discussion time was captured.

The number of people who contributed to the discussion including the chair was captured. The data was entered into an excel sheet. For the purpose of this study the following: age, gender, duration of symptoms, diagnosis, tumor location, size, lymph node status, ECOG status, co-morbidities such as diabetes mellitus and HIV, agreement between clinical and histopathological diagnosis and board recommendation were extracted. All new cases with malignant or complex benign neoplasms were discussed. However, we excluded diseases of the thyroid, recurrences or ongoing tumors.

The numbers of discussants were grouped into 3 categories $\leq 4,5-8$ and $\geq 9$. Additionally we categorized the time of discussion and number of discussants into short/long and few/many respectively using both mean and mode of each. This allowed us to compare the groups created. We went on to categorize age into three groups 30 and below, 31-60, 61+ for purposes of analysis. Finally we fitted a multinomial regression model with time of discussion as the dependent variable. P value $<0.05$ was considered statistically significant.

\section{Results}

The overall mean age of the 144 patients was $47.7 \pm 17.8$ and a median of 50 years. About $73 \%$ (105) were male and two patients the gender was not captured. Only four patients had complex benign lesions and one had metastatic prostate cancer. Tumor site included oral cavity 50 (34.7\%) neck masses 31 (21.5\%) larynx $22(15.3 \%)$ oropharynx $14(9.7 \%)$ the other sites $25(18.6 \%)$.

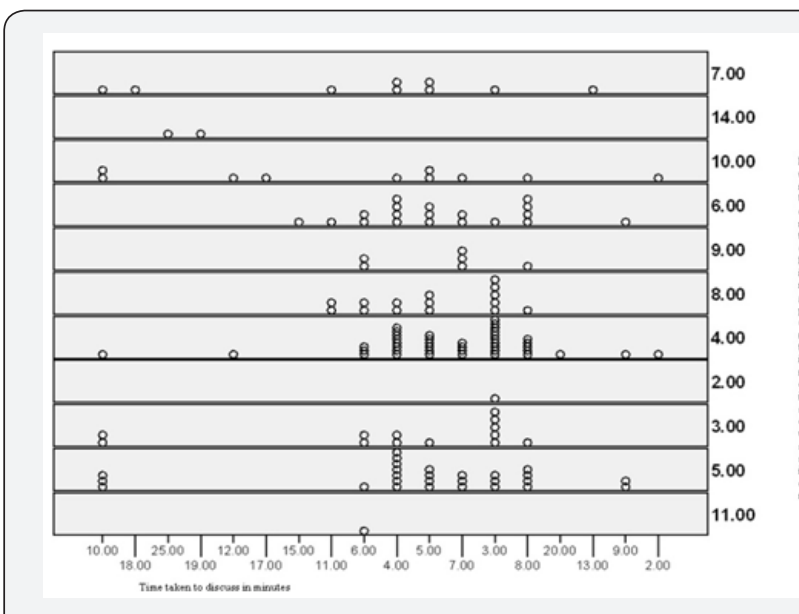

Figure 1: The number of discussant affected the time taken on each case.

The median, average and mode time taken to discuss cases was 5, 6.3 and 3 minutes respectively. The total time was 907 minutes and standard deviation 3.7 minutes. The median number of people discussing a case was 5 (range 3-14) while the mode was 4 and mean about 6 . The discussions were longer the higher the number of people who participated $r_{s}=0.25 p=0.003$ (Figure 1). We used the median and mode as cut offs to group our data into long and short discussions and did likewise for the number of discussants into many and few, the chi tests were $0.89 \mathrm{~d}_{\mathrm{f}}=1, \mathrm{p}=0.35$ and $7.47, \mathrm{~d}_{\mathrm{f}}=1, \mathrm{p}=0.006$ respectively. There was significant difference when the data was grouped using the mode. The mean duration of discussion when we used the mode discussion time as cut off to group our data into two was 5.4 minutes and 6.9 minutes respectively. 


\section{Journal of Tumor Medicine \& Prevention}

There was no correlation between age of the patient and the time taken to discuss cases $\left(r_{s}=0.13, p=0.11\right)$. However when age was grouped into three categories there was significant

Table 1: The relationship between other factors and time taken.

\begin{tabular}{|c|c|c|c|c|c|c|}
\hline & No of Patients & Up to 4 Minutes & 5-8 Minutes & 9 plus Minutes & Mean Time & P Value \\
\hline Total & 144 & 56 & 62 & 26 & & \\
\hline \multicolumn{7}{|c|}{ Gender } \\
\hline Male & 106 & 41 & 51 & 14 & 6.02 & \multirow{2}{*}{0.06} \\
\hline Female & 38 & 15 & 11 & 12 & 7.32 & \\
\hline \multicolumn{7}{|c|}{ Type } \\
\hline Complex benign & 8 & 2 & 3 & 3 & 6.27 & \multirow{2}{*}{0.23} \\
\hline Malignant & 136 & 54 & 59 & 23 & 7.87 & \\
\hline \multicolumn{7}{|c|}{ Age group } \\
\hline 30 and below & 32 & 10 & 12 & 10 & 8.19 & \multirow{3}{*}{0.04} \\
\hline $31-60$ & 76 & 32 & 35 & 9 & 5.68 & \\
\hline $61+$ & 35 & 14 & 15 & 6 & 6.11 & \\
\hline \multicolumn{7}{|c|}{ Site } \\
\hline Larynx & 21 & 4 & 14 & 3 & 6.29 & \multirow{5}{*}{0.12} \\
\hline Oral & 49 & 23 & 17 & 9 & 5.80 & \\
\hline Oral pharynx & 15 & 2 & 8 & 5 & 8.60 & \\
\hline Cervical & 34 & 17 & 11 & 6 & 6.06 & \\
\hline Other & 25 & 10 & 12 & 3 & 6.64 & \\
\hline \multicolumn{7}{|c|}{ T stage } \\
\hline $\mathrm{T} 1-\mathrm{T} 2$ & 17 & 6 & 9 & 2 & 6.47 & \multirow{4}{*}{0.31} \\
\hline T3 & 29 & 9 & 16 & 4 & 5.75 & \\
\hline $\mathrm{T} 4$ & 83 & 37 & 31 & 15 & 6.27 & \\
\hline $\begin{array}{l}\text { Not captured or } \\
\text { done }\end{array}$ & 15 & 4 & 6 & 5 & 7.93 & \\
\hline \multicolumn{7}{|c|}{ Nodal involvement } \\
\hline No & 25 & 6 & 14 & 5 & 6.68 & \multirow{5}{*}{0.70} \\
\hline $\mathrm{N} 1$ & 25 & 14 & 8 & 3 & 5.44 & \\
\hline $\mathrm{N} 2$ & 28 & 14 & 10 & 4 & 6.78 & \\
\hline N3 & 46 & 15 & 21 & 10 & 6.50 & \\
\hline Not accessed & 20 & 7 & 9 & 4 & 6.36 & \\
\hline \multicolumn{7}{|c|}{ Management } \\
\hline Radiotherapy & 30 & 10 & 17 & 3 & 6.2 & \multirow{6}{*}{0.03} \\
\hline Chemotherapy & 6 & 2 & 2 & 2 & 7.66 & \\
\hline More investigation & 29 & 6 & 12 & 11 & 8.96 & \\
\hline $\begin{array}{c}\text { Chemo } \\
\text { radiotherapy }\end{array}$ & 48 & 27 & 16 & 5 & 5.20 & \\
\hline Surgery & 20 & 8 & 9 & 3 & 5.50 & \\
\hline Others & 11 & 3 & 6 & 2 & 5.90 & \\
\hline \multicolumn{7}{|c|}{ Clin/Histo agree } \\
\hline Yes & 101 & 9 & 20 & 12 & 8.49 & \multirow{2}{*}{0.01} \\
\hline No & 43 & 47 & 42 & 14 & 5.46 & \\
\hline \multicolumn{7}{|c|}{ ECOG status } \\
\hline
\end{tabular}

relationship between time taken to discuss and amalgamated age. The relationship between other factors and time taken to discuss are as shown (Table 1). 
Journal of Tumor Medicine \& Prevention

\begin{tabular}{|c|c|c|c|c|c|c|}
\hline Not specified & 32 & 13 & 15 & 4 & 5.84 & \multirow{4}{*}{0.90} \\
\hline 1 & 55 & 22 & 23 & 10 & 6.34 & \\
\hline 2 & 38 & 14 & 18 & 6 & 6.39 & \\
\hline 3 & 11 & 5 & 3 & 3 & 6.45 & \\
\hline \multicolumn{7}{|c|}{ Co-morbidities } \\
\hline Yes & 117 & 48 & 48 & 21 & 6.15 & \multirow{2}{*}{0.14} \\
\hline No & 27 & 8 & 14 & 5 & 7.23 & \\
\hline \multicolumn{7}{|c|}{ Discussants } \\
\hline$\leq 4$ & 55 & 27 & 22 & 6 & 5.49 & \multirow{3}{*}{0.01} \\
\hline $5-8$ & 76 & 29 & 33 & 14 & 6.25 & \\
\hline$\geq 9$ & 13 & 0 & 7 & 6 & 10.77 & \\
\hline
\end{tabular}

When we tried fitting a model using multinomial logistic regression, only number of discussants and disagreement between clinical picture and the histopathological results significantly affected the time taken to discuss cases. The age group and tumor board recommendation were removed from the model hence the model was "time of discussion=126+133 clinical histopathological disagreement+130 number of discussants" ( $p=0.009$ and 0.035 respectively) $\chi^{2}=11.46 p=0.003$.

\section{Discussion}

From our search this is the first report to address factors that influence time taken to discuss patients at multi disciplinary team tumor board meeting of the head and neck from the Sub Saharan African Region. Given the demands on the few clinicians in Sub Saharan African region, it's imperative that multi-disciplinary tumor board meetings are as brief but effective as possible. Unfortunately we averaged 5 minutes per case compared to less than 2 and 3 minutes in studies done on head and neck cancer and colorectal cancer in the United Kingdom respectively $[8,9]$. Therefore studies like ours are essential if we are to cut down on time per patient and use it to discuss more patients.

The study found out that age affected the time taken to discuss patients with more spent on those 30 years and below. This was contrary to a report from United Kingdom that showed longer discussions for older patients [8]. In fact as shown in (Table 2), there was no difference in gender or clinical/histopathological agreement between the age groups. Additionally this is in lieu of the fact that there was neither statistically significant difference among the age groups by tumor $\mathrm{T}$ stage nor nodal $\mathrm{N}$ involvement by age group. Therefore the tendency may be driven by concerns clinicians have for quality and quantity of life the younger patient ought to have ahead of them as the decision on treatment is being made, however, it is a fact worth exploring farther.

Table 2: There was no difference in gender or clinical/histopathological agreement between the age groups.

\begin{tabular}{|c|c|c|c|c|c|}
\hline \multirow{2}{*}{ Age group } & \multicolumn{2}{|c|}{ Clinical Histopathological Agreement } & \multicolumn{2}{|c|}{ Gender } & \multirow{2}{*}{ Total } \\
\cline { 2 - 5 } & No & Yes & F & 16 & 32 \\
\hline$\geq 30$ & 17 & 15 & 16 & 61 & 76 \\
\hline $31-60$ & 19 & 57 & 15 & 28 & 35 \\
\hline $61+$ & 7 & 28 & 7 & 2 \\
\hline
\end{tabular}

Interestingly the management decision reached by the board also affected the time for discussion significantly unlike Mullan et al. [8] study. The difference is likely due to multiple factors such as challenges in accessing both surgical and radiotherapy services in Uganda. The surgical services are over stretched and so is radiotherapy $[4,10,11]$. Under such circumstances the role of the medical oncologist in head and neck cancers takes on a bigger influence than may be elsewhere. In light of the challenges of accessing surgical and radiotherapy services, many times we call on medical oncologist to give induction chemotherapy as a way of controlling disease to buy us time to get the patient the recommended treatment. This is different from the enhanced role of medical oncologists that has been reported in other settings [12]. It would be interesting to study the impact of this forced treatment decision has on outcomes of our patients since the scarcity of both services is likely to keep getting worse given the rising population and life expectancy levels.

We captured the agreement between clinical suspicion/ features with histopathological results and the disagreement had a very significant effect on time for discussion. This can be likened to incomplete investigation workup reported by Mullan et al. [8]. The background to this is the reliance on only hematoxylin and eosin stains to reach a final diagnosis. Immuno histochemical staining is still hard to come by and most patients can't afford it yet it's not provided for in public health care facilities. Given the lessons learnt from Burkitt's lymphoma and lymphomas at large, improvements in the area of histopathology are vital for both patient and research purposes $[13,14]$. In the tumor board we spent more time on patients who need a review of the histopathology results, repeat biopsy or when we had 
to insist on immunochemical staining before we can decide on management. Unfortunately we no longer have any attending pathologist attached to the head and neck tumor board thus we miss out on their direct input yet it has been shown to be beneficial to have pathologist participating in these boards [15].

Similar to Mullan et al. [8] study, we also found out that the number of discussant affected the time taken on each case as shown in (Figure 1). This and the clinical/histopathological disagreement were the only factors that were significantly associated with time taken per case when we fitted a multinomial model ( $p=0.009$ and 0.035 respectively) $\chi^{2}=11.46 p=0.003$. However, there was no significant difference in number of clinical/histopathological disagreement and the three discussant groups shown in (Table 1) $\left(\chi^{2}=2.78, \mathrm{~d}_{\mathrm{f}}=2, \mathrm{p}=0.25\right)$.

The study was limited in several ways including timing accuracy. This was a challenge in deciding what time was spent on discussing issues not relevant to the patient management such as teaching and sharing of anecdotal experiences. Additionally we didn't capture the time per specialist against the specialist and final treatment recommendation which could have been helpful. The changes in number and persons on discussion board were not captured yet different personalities will take longer when they have the floor compared to others. However, despite the shortfalls we believe this can be the first in many studies that will improve running of tumor boards in Sub Saharan Africa.

All in all the histopathology services in government tertiary health facilities need to be upgraded to add immune histochemistry services as a routine so as to aid in cases that are not clear cut. This will go a long way in saving time for the clinicians as well as the patients.

\section{Results}

The mean age of the 144 patients discussed in 30 sessions was $47.7 \pm 17.8$ with a median of 50 years. The median number of people discussing a case was 5 (range 3-14) while the mode was 4 and mean about 6 . The discussions were longer the higher the number of people who participated $\left(\mathrm{r}_{\mathrm{s}}=0.25 \mathrm{p}=0.003\right.$. When we fitted a model using multinomial logistic regression, only number of discussants and disagreement between clinical picture and the histopathological results significantly affected the time taken to discuss cases.

\section{Conclusion}

The factors that affect the time of discussion at MDTBs in developing countries may be unique and as such research at different centers are needed so as to come up with comprehensive steps in making these boards more efficient.

\section{Acknowledgement}

Adriane Kamulegeya is a NURTURE Fellow Grant number D43TW010132.

\section{References}

1. Dobrossy L (2005) Epidemiology of head and neck cancer: Magnitude of the problem. Cancer Metasasis 24(1): 9-17.

2. Wabinga HR, Nambooze S, Amulen PM, Okello C, Mbus L, et al. (2014) Trends in the incidence of cancer in kampala Uganda 1991-2010. Int J Cancer 135(2): 432-439.

3. Jemal A, Bray F, Center MM, Ferlay J, Ward E, et al. (2011) Global cancer Statistics. CA Cancer J Clin 61(2): 69-90.

4. Luboga S, Macfarlane SB, Schreeb J Von, Kruk ME, Cherian MN, et al. (2009) Increasing Access to Surgical Services in Sub-Saharan Africa: Priorities for National and International Agencies Recommended by the Bellagio Essential Surgery Group. PLoS Med 6(12): e1000200-e1000500.

5. Abdel-Wahab M, Bourque JM, Pynda Y, Iżewska J, Van der Merwe D (2013) Status of radiotherapy resources in Africa: an International. Lancet Oncol 14(4): e168-e175.

6. Page AJ, Cosgrove D, Elnahal SM, Herman JM, Pawlik TM, et al. (2014) Organizing a multidisciplinary clinic. Chinese Clin Oncol 3(4): 43(1-8).

7. Saghir NEI, Charara RN, Kreidieh FY, Eaton V, Rania AF (2015) Global Practice and Efficiency of Multidisciplinary Tumor Boards : Results of an American Society of Clinical Oncology. J Glob Oncol 1(2): 57-64.

8. Mullan BJ, Brown JS, Lowe D, Rogers SN, Shaw RJ (2014) Analysis of time taken to discuss new patients with head and neck cancer in multidisciplinary team meetings. Br J Oral Maxillofac Surg 52(2): 128133.

9. Shah S, Arora S, Atkin G, Glynne-Jones R, Mathur P, et al. (2014) Decision-making in Colorectal Cancer Tumor Board meetings : Results of a prospective observational assessment. Surg Endosc 28(10): 27832788.

10. Durosinmi-Etti FA, Nofal M, Mahfouz MM (1991) Radiotherapy in Africa: Current needs and prospects. IAEA Bull 4: 24-28.

11. Kigula MJB, Wegoye P (2000) Pattern and experience with cancers treated with the chinese GWGP80 cobalt unit at Mulago hospital, Kampala. East Afr Med J 77(10): 523-525.

12. Choong N, Vokes E (2008) Expanding Role of the Medical Oncologist in the Management of Head and Neck Cancer. CA Cancer J Clin 58(1): 32-53.

13. Orem J, Sandin S, Weibull CE, Odida M, Webinga H, et al. (2012) Agreement between diagnoses of childhood lymphoma assigned in Uganda and by an international reference laboratory. Clin Epidemiol 4: 339-347

14. Ogwang DM, Weiqiang Z, Ayers WL, Mbulaiteye SM (2011) Accuracy of Burkitt lymphoma diagnosis in constrained Pathology settings: Importance to epidemiology. Arch Pathol Lab Med 135(4): 445-450.

15. Strobel SL (2006) Enhancing the Pathologist's Role at Hospital Tumor Boards. Ann Clin Lab Sci 36(3): 243-247. 
This work is licensed under Creative Commons Attribution 4.0 Licens

DOI: 10.19080/JTMP.2017.01.555565
Your next submission with Juniper Publishers will reach you the below assets

- Quality Editorial service

- Swift Peer Review

- Reprints availability

- E-prints Service

- Manuscript Podcast for convenient understanding

- Global attainment for your research

- Manuscript accessibility in different formats ( Pdf, E-pub, Full Text, Audio)

- Unceasing customer service

Track the below URL for one-step submission https://juniperpublishers.com/online-submission.php 